\title{
CHRONIC DISEASES ARE STRONGLY ASSOCIATED WITH SICKNESS ABSENCES IN A SAMPLE OF ITALIAN PUBLIC EMPLOYEES
}

\author{
ENRICO CASIMIRRI ${ }^{1}$, ALICE VACCARI ${ }^{1}$, MICHELA SCHITO ${ }^{1}$, MELISSA BONCI, \\ MARIARITA STENDARDO ${ }^{1}$, ARMANDO STEFANATI ${ }^{1}$, MARCO NARDINI ${ }^{2}$, and PIERA BOSCHETTO ${ }^{1}$ \\ ${ }^{1}$ University of Ferrara, Ferrara, Italy \\ Department of Medical Sciences \\ ${ }^{2}$ University Hospital and Public Health Service of Ferrara, Ferrara, Italy \\ Department of Prevention and Protection
}

\begin{abstract}
Objectives: Data on the prevalence of chronic diseases and their relationship with sickness absence in the Italian public employees are rather scarce. Therefore, in the first place, we assessed the distribution of chronic diseases in the employees of the University of Ferrara. As a next step, we investigated the possible associations between each chronic disease and cumulative days of all-cause sickness absence, and finally we investigated the odds ratio of each single chronic disease on sickness absence. Material and Methods: A total of 514 employees, 269 sick-listed and 245 not sick-listed in 2012, were studied. Demographical/clinical characteristics and chronic diseases were obtained from all study participants during medical surveillance procedures. Sickness absence days and job seniority data were obtained from the administrative office. Results: Gastrointestinal and psychiatric diseases were the most reported in the sick-listed sample $(\mathrm{p}=0.01$ and $\mathrm{p}=0.02$, respectively, compared to the not sick-listed). In the interquantile regression analysis, the sickness absence days were associated with psychiatric diseases $(\beta=65.1,95 \% \mathrm{CI}: 13.2-117.1, \mathrm{p}=0.01)$ and with the presence of 2 or more chronic diseases $(\beta=23.3,95 \% \mathrm{CI}: 4.5-42, \mathrm{p}=0.02)$. Furthermore, the logistic regression analysis showed that the odds of sickness absence were increased 2 fold by psychiatric diseases ( $\mathrm{OR}=2.2,95 \% \mathrm{CI}: 1.01-4.93, \mathrm{p}=0.04)$, and gastrointestinal diseases $(\mathrm{OR}=1.9,95 \% \mathrm{CI}: 1.07-3.42, \mathrm{p}=0.02)$ and, to a lesser extent, by high body mass index (OR = 1.05, 95\% CI: $1-1.11$, $\mathrm{p}=0.03)$. Conversely, female gender reduced by half the odds of sickness absence (OR $=0.5,95 \% \mathrm{CI}: 0.3-0.8, \mathrm{p}=0.04)$. Conclusions: This study highlights the relevant association between chronic diseases and sickness absence in Italian public employees. Our findings indicate the importance of considering the health status when designing preventive interventions aimed at decreasing sickness absences in this population.
\end{abstract}

Key words:

Sickness absence, Chronic diseases, Occupational health, Gastrointestinal diseases, Psychiatric diseases

\section{INTRODUCTION}

Sickness absence is a medical problem frequently used as an indicator of health [1,2]. This phenomenon has an important economic impact in terms of loss of productivity, employment, replacement and insurance costs. Sickness absence has also been shown to predict future adverse health outcomes, mortality and increased future risk of disability pension in an ageing workforce $[1,3,4]$.

The ageing of the working population is a crucial issue in modern society. In Europe, the employment rate of

Received: September 24, 2013. Accepted: February 24, 2014.

Corresponding author: P. Boschetto, Dipartimento di Scienze Mediche, Sezione di Medicina di Sanità Pubblica, Via Fossato di Mortara 64/b, 44100 Ferrara, Italy (e-mail: bsp@unife.it). 
workers aged 55-64 increased from 36\% in 1999 to $49 \%$ in 2012 and, in Italy, these older workers constitute more than one-half of the workforce in several areas [5].

As chronic diseases are strongly related to age [6,7], the number of unhealthy workers is increasing. In 2012, 36\% of the Italian population aged 45-54 was affected by at least one chronic disease and $13 \%$ by 3 concomitant illnesses [8].

Chronic diseases and sickness absence appear to be correlated; indeed chronic diseases can predict long-term sickness absence and disability pension [9,10]. Moreover, the risk of sickness absence seems to be higher in people with 2 or more chronic conditions [10-12].

A number of studies show that sickness absence rate is high in Italian public employees; according to the data from the Italian Ministry of Economics, the total number of days off work for sickness absence in Italian public employees was 1096753 in 2012 [13,14]. Curiously, employment in the Italian public sector appears to be an important predictor of sickness absence in the Italian working population [15].

Several studies have examined the influence of various work-related aspects (sick leave compensation policies, factors related to contractual and institutional aspects) on sickness absence in Italian public employees [16,17]. However, little attention has been paid to the contribution of health-related determinants. Particularly, little is known about the prevalence of chronic diseases and their possible impact on sickness absence in the specific population of the middle aged Italian public employees. So far, most of the studies on the determinants of sickness absence have focused on heterogeneous populations of workers with an age range between 18 and 65 years $[18,19]$.

Lundl et al. [18] examined 2 cross-sectional samples of 8562 Swedish and Danish public sector employees: clerks, personal and protective service workers, skilled agricultural and fishery workers, craft and related trade workers, showing that sickness absence was associated with a body mass index (BMI) above normal values, former and current smoking, musculoskeletal symptoms and low self-rated health status. Nevertheless, in this as well as other studies, middle age white collar employees are underrepresented [20]. Furthermore, most of the previous investigations addressed the effect of a single chronic disease on sickness absence [21-23].

In a prospective cluster-randomized controlled trial of 158 subjects, Arends et al. [23] focused on workers with psychiatric disorders, demonstrating that medication, company size, and conflicts with supervisor predicted the incidence of recurrent sickness absence. By contrast, surveys exploring the total burden of chronic diseases on sickness absence are less common. Only 2 population-based studies have been carried out and have indicated that people with chronic diseases have increased risk of sickness absence $[24,25]$. So, little remains known about the association between the total burden of chronic diseases and sickness absence in specific worker categories.

Therefore, the aims of our study were:

- to assess the distribution of chronic diseases in a sample of Italian public employees,

- to evaluate the possible associations between chronic diseases and cumulative days of all-cause sickness absence,

- to investigate the odds ratio of the "individual" chronic diseases on sickness absence.

\section{MATERIAL AND METHODS}

\section{Study design and population characteristics}

The study design was cross-sectional. A total of 514 university permanent administrative employees who underwent medical surveillance procedures from the 1st January to the 31st December 2012 were studied.

The eligibility criteria were: exposure to at least one occupational risk factor according to the Italian 
occupational health and safety legislation. According to this legislation, workers must undergo medical surveillance procedure. Therefore, the participation rate was 100/100.

Demographic/clinical data, smoking history, BMI, mean arterial pressure (MAP) and burden of chronic diseases were collected from all study participants by authorized medical personnel during the medical surveillance visit at the Occupational Medicine Service of the University of Ferrara.

The sickness absence, sickness absence days and job seniority data were obtained for each worker from the administrative registers of the University of Ferrara personnel office.

Subjects were divided into the following 2 groups:

- The sick-listed sample $(\mathrm{N}=269)$ - consisted of all individuals who were registered as sick-listed at the University of Ferrara personnel office during the inclusion period of 1st January to 31st December 2012.

- The not sick-listed sample $(\mathrm{N}=245)$ - included individuals who had no sickness absences in 2012.

\section{MEASUREMENTS}

\section{Sickness absence and sickness absence days}

The sickness absence refers to at least one absence from work due to health problems in 2012. We were not allowed to know the exact diagnosis of the health problems because of the Italian regulations on privacy.

A dichotomous variable was obtained with categories "yes" in case of presence of sickness absence and "no" in case of no presence. Because of our interest primarily in sickness absence due to health problems, absences related to pregnancy or accident/injury were not considered.

The sickness absence days refer to the cumulative workdays each employee was absent from work due to all-cause sickness in the year 2012. Because our measure of accumulated number of days of sickness is independent of the number of absence spells, the term refers to the total days of sickness absence in 2012.

\section{Chronic diseases and clinical measurements Chronic diseases}

The chronic diseases burden was self-reported and assessed from the medical history of subjects. The diseases were categorized into ten different groups (musculoskeletal, endocrine, cardiovascular, gastrointestinal, genitourinary, neurologic, respiratory, eye diseases, psychiatric and neoplastic diseases) during data processing. Dichotomous variables were obtained from the above-mentioned chronic diseases with categories "yes" if one of the above diseases was reported vs. "no" if not reported. The definition of chronic disease or chronic condition is not agreed upon in literature. According to the World Health Organization (WHO), chronic diseases have a long duration and usually slow progression [26]. The term chronic disease will be used when referring to the aforementioned disease groups.

Pack years (P/Y)

Pack-years of smoking were calculated by multiplying the number of cigarettes per day by the number of years smoked and dividing the product by 20 .

\section{Body mass index (BMI)}

Height and weight of each participant were measured and body mass index calculated $\left(\mathrm{kg} / \mathrm{m}^{2}\right)$.

Blood pressure and mean arterial pressure (MAP)

Diastolic and systolic resting blood pressure was measured with an Erkameter 3000 mercury sphygmomanometer, in a sitting relaxed position, in a quiet room, after at least a 10-min rest. The blood pressure was measured 3 times [27,28] and the average of the last 2 measures was calculated. All measurements were taken by trained medical personnel. Mean arterial pressure (MAP) 
was calculated by adding $2 / 3$ of diastolic blood pressure with $1 / 3$ of systolic blood pressure [29].

\section{Ethics}

All participants gave their written informed consent. The study was approved by the local Ethics Committee and performed in accordance with the ethical standards laid down in the 1964 Declaration of Helsinki and its later amendments.

\section{Statistical analysis}

The Shapiro-Wilk test was used to test the normal distribution of quantitative variables. When quantitative variables were normally distributed, the results were expressed as mean values and standard deviation (SD), otherwise median and interquartile range (IQR; 25-75th percentile) were reported, also $95 \%$ confidence interval (CI) was calculated; qualitative variables were summarized as counts and percentages. The comparison between groups of qualitative variables was performed using a Chi ${ }^{2}$ test or Fisher's exact test, as appropriate. Continuous variables were compared among groups by ANOVA if normally distributed and by the KruskalWallis/Mann Whitney tests if non-normally distributed. Spearman's correlation coefficient was used to test correlation between 2 variables.

Since the distribution of the sickness absence days in the sick-listed group was not normal, the interquantile regression was used for the multivariate model to assess the associations between sickness absence days and both chronic diseases and clinical variables (age, BMI, P/Y) [30].

The odds ratios (OR) with corresponding 95\% CI were obtained using multivariate logistic regression analysis in order to model the effect of chronic diseases, job seniority and clinical variables on the risk of sickness absence in the study population.

Data analysis was performed with Stata statistical package (release 11.1, 2010, Stata Corporation).

\section{RESULTS}

\section{General characteristics of the study population}

We analyzed data from a total of 514 subjects: 269 sicklisted and 245 not sick-listed in 2012 (Table 1).

The mean age of the general population was $48 \pm 7.8$ years; $69 \%$ were females and the median job seniority was 17 years (IQR 8-25). Body mass index and MAP were higher in males than in females (BMI: $26 \pm 4.2$ vs. $23 \pm 4.1 ; p<0.01$; MAP: $97 \pm 9.8$ vs. $90 \pm 12.1 \mathrm{~mm} \mathrm{Hg}$; $\mathrm{p}<0.01)$.

Clinical variables (age, BMI, MAP) did not differ between the not sick-listed and sick-listed groups; whereas $\mathrm{P} / \mathrm{Y}$ ( 8.3 vs. $6.9 ; \mathrm{p}=0.19$ ) and job seniority (18 vs. 16 years; $\mathrm{p}=0.9$ ) were slightly higher, but not significantly, in the latter group (Table 1).

Notably, $80 \%$ of our total employees were affected by at least one chronic disease and the distribution of subjects with one or more chronic conditions was similar in both sick-listed and not sick-listed groups. The mean age was significantly higher in subjects with at least one chronic disease than in those without ( $49 \pm 7.5$ vs. $44 \pm 8.1$ years; $p<0.01$ ). Conversely, job seniority was similar between employees affected and not affected by chronic conditions (16 (IQR 8-23) vs. 19 (IQR 11-26) years; $\mathrm{p}=0.1$ ).

\section{Chronic diseases and sickness absence}

The more frequent chronic diseases in the study population were: musculoskeletal (36\%), endocrine (16\%), cardiovascular $(16 \%)$, gastrointestinal $(13 \%)$, genitourinary (12\%), neurologic (10\%) and psychiatric (7\%). Distribution of chronic conditions was similar between males and females. Gastrointestinal (9\% vs. 4\%; $\mathrm{p}=0.01)$ and psychiatric (5\% vs. $2 \% ; \mathrm{p}=0.02)$ diseases were the most frequently reported in the sick-listed group, whereas the genitourinary diseases were the most common in the not sick-listed one (11\% vs. $1 \%$; $\mathrm{p}<0.01$ ) (Figure 1). 
Table 1. General characteristics of study groups

\begin{tabular}{|c|c|c|c|c|}
\hline \multirow[b]{2}{*}{ Variable } & \multicolumn{3}{|c|}{ Respondents } & \multirow[b]{2}{*}{$\mathrm{p}$} \\
\hline & $\begin{array}{c}\text { total } \\
(\mathrm{N}=514)\end{array}$ & $\begin{array}{l}\text { sick-listed } \\
(\mathrm{N}=269)\end{array}$ & $\begin{array}{l}\text { not sick-listed } \\
(\mathrm{N}=245)\end{array}$ & \\
\hline Age (years) $(\mathrm{M} \pm \mathrm{SD})$ & $48 \pm 7.8$ & $47.8 \pm 7.6$ & $48 \pm 8.1$ & 0.70 \\
\hline Females $[\mathrm{n}(\%)]$ & $353(69)$ & $199(74)$ & $154(63)$ & 0.60 \\
\hline Body mass index $\left(\mathrm{kg} / \mathrm{m}^{2}\right)(\mathrm{M} \pm \mathrm{SD})$ & $24.1 \pm 4.3$ & $24.2 \pm 4.4$ & $23.8 \pm 4.2$ & 0.50 \\
\hline Mean arterial pressure $(\mathrm{mm} \mathrm{Hg})(\mathrm{M} \pm \mathrm{SD})$ & $92.4 \pm 12$ & $91.7 \pm 12.2$ & $93.3 \pm 11.6$ & 0.15 \\
\hline \multicolumn{5}{|l|}{ Smoking } \\
\hline pack/years [Me (interquartile ranges: $25-75$ th percentile)] & $7.5(2.5-18)$ & $8.3(2.1-18.2)$ & $6.9(2.9-18)$ & 0.19 \\
\hline current smokers $[\mathrm{n}(\%)]$ & $97(19)$ & $45(17)$ & $52(21)$ & 0.30 \\
\hline ex-smokers $[\mathrm{n}(\%)]$ & $78(15)$ & $39(14)$ & $39(16)$ & 0.30 \\
\hline Sick leave (days) $(\mathrm{M} \pm \mathrm{SD})$ & $6.4 \pm 15.2$ & $12.2 \pm 19.3$ & 0 & $<0.001$ \\
\hline Job seniority (years) & $17(8-25)$ & $18(8-24)$ & $16(8-26)$ & 0.90 \\
\hline \multicolumn{5}{|l|}{ Chronic diseases [n (\%)] } \\
\hline$\geq 2$ & $243(47)$ & $134(50)$ & $109(45)$ & 0.20 \\
\hline 1 & $167(33)$ & $83(31)$ & $84(34)$ & 0.90 \\
\hline 0 & $104(20)$ & $52(19)$ & $52(21)$ & 0.60 \\
\hline
\end{tabular}

M - mean; SD - standard deviation; Me - median.

The sickness absence days were higher in employees affected by psychiatric $(18.1 \pm 30.2$ vs. $5.5 \pm 13.2$ days; $\mathrm{p}<0.01)$

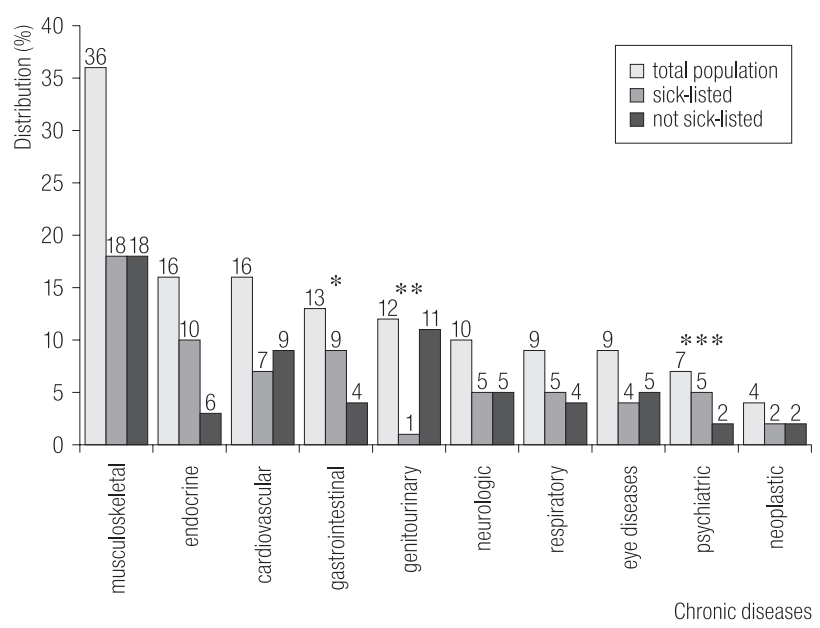

The most frequently reported diseases include musculoskeletal in the overall study population, gastrointestinal and psychiatric in the sicklisted, and genitourinary diseases in the not sick-listed group.

$* \mathrm{p}=0.01 ;{ }^{* *} \mathrm{p}<0.01 ; * * \mathrm{p}=0.02$.

Fig. 1. Chronic diseases in the general population and the study groups or gastrointestinal diseases $(10.7 \pm 21.7$ vs. $5.7 \pm 13.9$ days; $\mathrm{p}<0.01)$ as compared to subjects without chronic conditions. Likewise, employees with 2 or more chronic illnesses had longer sickness absence than healthy subjects $(9.3 \pm 20.7$ vs. $3.7 \pm 6.4$ days; $p=0.05)$. Although females were the majority of our population, the sickness absence was longer in males ( $6.6 \pm 18$ vs. $6.2 \pm 1.8$ days; $\mathrm{p}=0.01$ ) (Figure 2).

\section{Associations between sickness absence days and clinical variables}

In the general population, we did not find significant associations between sickness absence days and clinical variables (age, P/Y, BMI, MAP) or job seniority. Only age was positively correlated with sickness absence days $(r=0.15, p=0.01)$ in the sick-listed group. In this group, the distribution of sickness absence days (median value: 5, range: 1-140) was not normal. In fact, they were almost entirely distributed between 

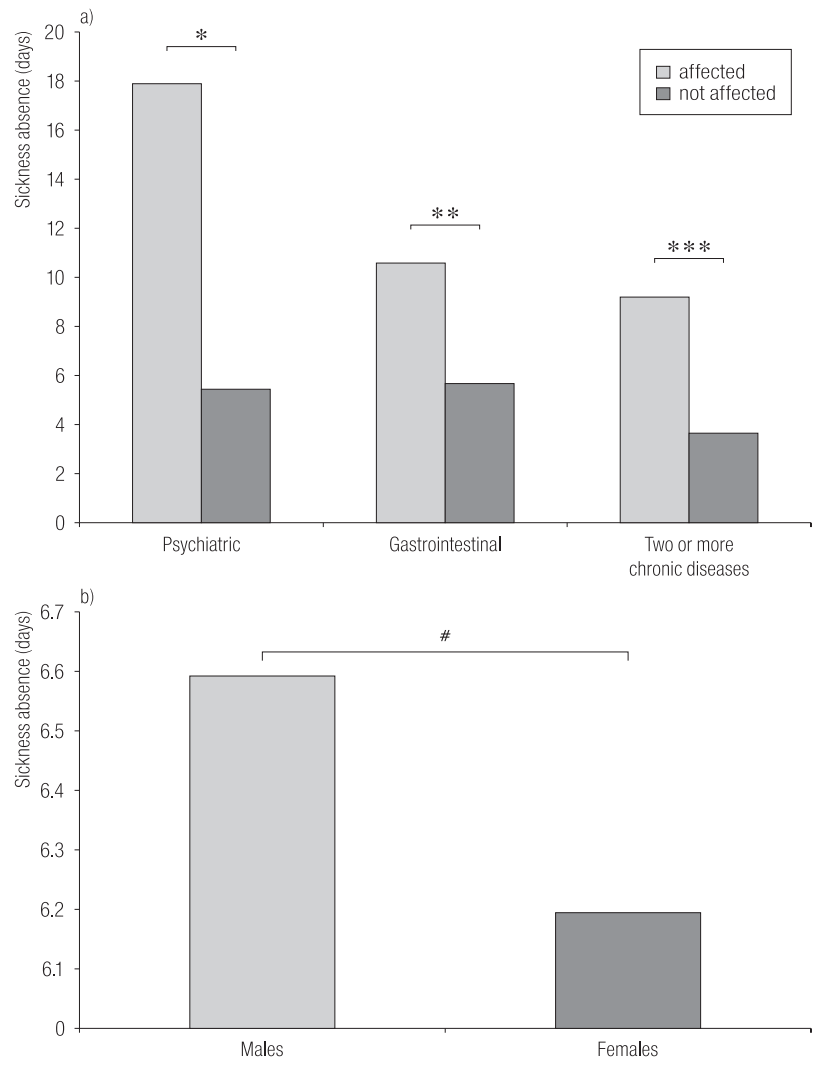

The sickness absence length was significantly higher in employees affected by psychiatric diseases, gastrointestinal diseases or 2 or more chronic conditions. Interestingly, female employees had a lower sickness absence length than males.

The top boundary of the bars indicates averages.

${ }^{*} \mathrm{p}<0.01 ;{ }^{* *} \mathrm{p}<0.01 ;{ }^{* * *} \mathrm{p}=0.05 ;{ }^{*} \mathrm{p}=0.01$.

Fig. 2. Sickness absence days - a) affected and not affected workers, b) gender the 25 th percentile ( 3 days) and the 95 th percentile (70 days). So, we performed the multiple interquantile regression analysis, which showed that sickness absence days were positively and independently associated with psychiatric diseases $(\beta=65.1,95 \%$ CI: $13.2-117.1, p=0.01)$ and with the presence of 2 or more chronic conditions $(\beta=23.3,95 \%$ CI: $4.5-42.6$, $\mathrm{p}=0.02)$. The calculated coefficient $\beta$ estimates the change in the 25-95th quantile range of our response variable (sickness absence days) produced by one unit change in the covariate (gastrointestinal diseases, psychiatric diseases, female gender, age, BMI, pack/years, job seniority, 2 or more chronic diseases) (Table 2). Therefore, the number of sickness absence days increased by 65.1 or 23.3 , being affected by psychiatric diseases or 2 or more chronic conditions. Furthermore, multivariate logistic regression analysis revealed a significant association between sickness absence and psychiatric, gastrointestinal diseases or high BMI (Table 3). Indeed, the odds of sickness absence in subjects affected by psychiatric or gastrointestinal diseases were almost 2 fold higher than those of individuals without these diseases $(\mathrm{OR}=2.2$ and 1.9, respectively) (Table 3). Curiously, the odds for sickness absence of the female gender was half of that of the males $(\mathrm{OR}=0.5)$ (Table 3$)$.

Table 2. Multiple interquantile regression analysis in sick-listed group with sickness absence days as dependent variable

\begin{tabular}{lrrccc}
\hline \multicolumn{1}{c}{ Variable } & \multicolumn{1}{c}{ SE } & t-test & 95\% CI & $\mathrm{p}$ \\
\hline Gastrointestinal diseases & 4.76 & 8.86 & 0.54 & $-12.70-22.2$ & 0.600 \\
Psychiatric diseases & 65.10 & 26.30 & 2.47 & $13.20-117.1$ & 0.014 \\
Female gender & 5.14 & 13.07 & 0.40 & $-20.60-30.9$ & 0.690 \\
Age & 0.45 & 0.34 & 1.29 & $-0.23-1.1$ & 0.200 \\
Body mass index & 0.42 & 0.98 & 0.43 & $-1.50-2.3$ & 0.660 \\
Pack/years & -0.62 & 0.42 & -1.46 & $-1.47-0.22$ & 0.140 \\
Job seniority & -0.17 & 0.35 & -0.48 & $-0.87-0.53$ & 0.630 \\
Two or more chronic diseases & 23.30 & 9.50 & 2.44 & $4.50-42$ & 0.020 \\
\hline
\end{tabular}

$\beta$ - interquantile regression coefficient; SE - standard error; CI - confidence interval. 
Table 3. Multiple logistic regression analysis with odds ratios (OR) and $95 \%$ confidence intervals $(95 \% \mathrm{CI}$ ) for sickness absence in the study population

\begin{tabular}{lccc}
\hline \multicolumn{1}{c}{ Variable } & OR & $95 \%$ CI & $\mathrm{p}$ \\
\hline Gastrointestinal diseases & 1.90 & $1.07-3.42$ & 0.02 \\
Psychiatric diseases & 2.20 & $1.01-4.93$ & 0.04 \\
Female gender & 0.50 & $0.32-0.80$ & 0.04 \\
Age & 0.99 & $0.97-1.02$ & 0.90 \\
Body mass index & 1.05 & $1.00-1.10$ & 0.03 \\
Pack/years & 0.98 & $0.96-1.00$ & 0.10 \\
Job seniority & 0.99 & $0.97-1.01$ & 0.50 \\
Two or more chronic diseases & 1.08 & $0.74-1.65$ & 0.70 \\
\hline
\end{tabular}

\section{DISCUSSION}

The results of this study showed that, while the musculoskeletal, endocrine and cardiovascular diseases were the most frequently reported chronic conditions in all the studied employees, the gastrointestinal and psychiatric illnesses were more common in the sick-listed than in the not sick-listed workers. In the former, the sickness absence period was independently associated with psychiatric diseases or with the presence of 2 or more chronic conditions. Furthermore, the odds of sickness absence were higher in subjects with psychiatric, gastrointestinal diseases or high BMI, whilst they were lower in the female gender. In our study, sick-listed subjects exhibited a higher burden of psychiatric and gastrointestinal diseases than not sick-listed ones. These data are consistent with those of Ármannsdóttir et al. [25] who demonstrated a higher prevalence of the same 2 illnesses in sick-listed Swedish workers compared to a general population of not sick-listed. However, in contrast with the results of these authors, we found that musculoskeletal, and neoplastic diseases were equally distributed between the 2 groups. Differences of the study population and study design might explain the partial discrepancies between the report of Ármannsdóttir et al. and ours: they performed a population-based survey where the subjects had different occupational positions and an age range (19-64 years) much wider than that of our public employees (40-56 years). Furthermore, the quoted authors do not consider sickness absences lasting 2 weeks or less, since in Sweden these absences are not registered as they are in Italy.

A higher number of sickness absence days was found in employees affected by psychiatric, gastrointestinal or 2 or more chronic diseases. In 2 very recent surveys, Soegaard et al. [31] and Jansson et al. [32] confirmed that workers affected by either psychiatric or gastrointestinal illnesses were more prone to take longer sickness absence than subjects unaffected by these 2 diseases. Furthermore, in a cross sectional study, Roskes et al. [33] showed that workers with chronic diseases had not only more frequent but also more prolonged sickness absence than healthy subjects.

To focus our attention on sick-listed employees, we determined the possible associations between sickness absence and both clinical characteristics and chronic diseases. In multiple interquantile regression analysis with sickness absence days as dependent variable, 2 or more chronic conditions or psychiatric, but not gastric, diseases were positively and independently associated with sickness absence length. These results suggested that psychiatric disorders and the presence of polimorbidities were the major determinants of long term sickness absence in this sample. In a very recent survey, Knudsen et al. [34] reported a significant association between psychiatric disorders and long-term sickness absences in a large population of workers and showed that workers with coexistence of 2 psychiatric diseases had longer duration of the first sickness absence episode.

Concerning the relationship between the presence of sickness absence and chronic conditions, psychiatric and gastrointestinal diseases were significantly associated with absences. In line with our findings, Overland et al. [35] demonstrated that gastrointestinal disorders were not only risk factors for sickness absence but also associated with the existence of psychiatric diseases. Furthermore, Stansfeld 
et al. [36] showed that the presence of common mental disorders predict future sickness absence in English public employees.

Another variable directly associated with the presence of sickness absence in our population was high BMI. Both overweight and obesity are associated with the incidence of multiple comorbidities, including type 2 diabetes, cancer and cardiovascular diseases [37]. The main mechanism responsible for this association seems to be an underlying low grade systemic inflammation due to production of cytokines by adipose tissue [38]. Korpela et al. [39] showed that BMI was not only a predictor of obesity associated health risks, but also of sickness absence. Finally, Harvey et al. [40] demonstrated that employees with high BMI take more frequent sickness absences than workers with healthy weight.

In our study, females exhibited a lower occurrence of sickness absence in 2012 and showed a shorter sickness absence length than males. These results may appear in contrast with the surveys of Ármannsdóttir et al. [25] and Laaksonen et al. [41], who reported a higher sickness absence rate in women than in men. However, unlike in our investigation, which focused on a relatively small, but homogeneous sample, these authors studied a larger but more heterogeneous population. We actually focused on permanent white collar workers employed in the Italian public sector and with a high mean age, whilst they studied younger permanent and temporary workers from public and private sectors, with occupations ranging from blue collar workers to managers.

Moreover, women with pregnancy-related sickness absence were included in the sick-listed workers group of the Laaksonen population study [41]. The female sickness absence rate differs between different countries, age classes, professional groups and seems to be context-sensitive [42]; therefore, our findings might be explained by the specific characteristics of our study population. Although the relationship between gender and sickness absence is well documented in scientific literature, the inverse association we observed between female gender and sickness absence deserves further investigation. Indeed, our data confirm and extend those of Duijts et al. [43] who reported the above mentioned inverse association, albeit weak, in a large meta-analysis focused on predictors of sickness absence due to psychosocial complaints, i.e. psychological conditions such as depression, and social problems such as work/family conflicts.

With regards to the possible pathway linking chronic diseases to sickness absence, the literature on this subject is not exhaustive. We know that workers affected by chronic diseases reported difficulties in meeting physical and psychosocial work demands [44]. They are affected by limitations caused by the disease, such as health complaints (fatigue, pain) or are troubled by symptoms of their specific chronic condition. Apart from disease symptoms and limitations, many chronically ill workers are also troubled by psychological distress or depression $[45,46]$.

This study has some limitations. We performed our investigation in a sample size of permanent administrative employees, and the sampling method might lead to a potential bias due to the inclusion criteria. However, to perform a 1-year study including all employees implies collecting all data solely from the registers, and this process may be far more biased than a sampling method.

Our data on chronic diseases were self-reported, so recall and reporting bias may have occurred. Nevertheless, because the university employees undergo periodical medical examinations as a part of the university occupational health surveillance program, we mitigated this bias by also analyzing the medical records collected from our Occupational Medicine Service's database.

The analysis of chronic diseases that may affect the incidence and duration of sickness absence should include at least a 3-year period [47]. Therefore, our short period observation could generate a bias related to an underrepresentation of chronic diseases in the sick-listed sample 
and to an underestimation of sickness absence days for individuals with specified chronic diseases. We are following up our study population in order to extend the period of analysis up to 3 years. At present, we think that the data for the first-year period might give some information, both because the study population was more than 500 employees and because the $80 \%$ of these employees were affected by a chronic disease.

Due to Italian privacy laws, we do not know specific sickness absence causes. Nevertheless, our data analysis and results strongly suggest that chronic diseases may affect all sickness absences and cumulative sickness absence length. Finally, the generalization of our results should be restricted to the specific population of the Italian public employees. Concerning the strengths, our study is focused on a very homogeneous and specific population of employees, sicklisted and not sick-listed, of the University of Ferrara. At variance with other investigations, no data is missing with regard to our population, thus we accurately analyzed the relationship between the presence of chronic diseases and sickness absence. Moreover, recorded sickness absence days and sickness absence data were acquired from legal university registers, excluding, therefore, bias related to self-reported sickness absence.

\section{CONCLUSIONS}

In conclusion, our results indicate that sick-listed employees of the University of Ferrara had higher frequency rate of psychiatric and gastrointestinal chronic diseases than not sick-listed. In the former, the sickness absence length was independently and positively associated with psychiatric illnesses and with the presence of 2 or more chronic conditions. Moreover, the odds of sickness absence were higher in subjects affected by psychiatric diseases, gastrointestinal diseases or with high BMI, whilst in the female gender the odds were lower. Females also showed a lower number of sickness absence days than males.
This study highlights the importance of taking workers chronic diseases and health status into account when designing preventive interventions aimed at decreasing sickness absence in public employees. Targeting long-term health problems may be an important factor in an attempt to improve the productivity and to reduce the sickness absence rates in chronically ill employees.

\section{ACKNOWLEDGEMENTS}

We thank Sabrina Trapani and Patrizia Vergnani for providing sickness absences records.

\section{REFERENCES}

1. Kivimaki M, Head J, Ferrie JE, Shipley MJ, Vahtera J, Marmot MG. Sickness absence as a global measure of health: Evidence from mortality in the Whitehall II prospective cohort study. BMJ. 2003;327(7411):364, http://dx.doi.org/10.1136/ bmj.327.7411.364.

2. Kivimaki M, Head J, Ferrie JE, Singh-Manoux A, Westerlund $\mathrm{H}$, Vahtera $\mathrm{J}$, et al. Sickness absence as a prognostic marker for common chronic conditions: Analysis of mortality in the GAZEL study. Occup Environ Med. 2008;65(12): 820-6, http://dx.doi.org/10.1136/oem.2007.038398.

3. Vahtera J, Westerlund H, Ferrie JE, Head J, Melchior M, Singh-Manoux A, et al. All-cause and diagnosis specific sickness absence as a predictor of sustained suboptimal health: A 14-year follow-up in the GAZEL cohort. J Epidemiol Community Health. 2010;64(4):311-7, http://dx.doi.org/10.1136/jech.2008.083923.

4. Wallman T, Wedel H, Palmer E, Rosengren A, Johansson S, Eriksson H, et al. Sick-leave track record and other potential predictors of a disability pension. A population based study of 8,218 men and women followed for 16 years. BMC Public Health. 2009;9:104, http://dx.doi.org/10.1186/1471-2458-9-104.

5. Online published data on employment rate stratified by age [Internet]. Eurostat 2012 [cited 2013 Jun 1]. Available 
from: http://epp.eurostat.ec.europa.eu/portal/page/portal/ eurostat/home.

6. Pomerleau J, Knai C, Nolte E. The burden of chronic disease in Europe. In: Nolte E, McKee M, editors. Caring for people with chronic conditions: A health system perspective. Maidenhead: McGraw-Hill; 2008. p. 15-42.

7. Busse R, Blümel M, Scheller-Kreinsen D, Zentne A. Tackling chronic disease in Europe: strategies, interventions and challenges. 1th ed. London: European Observatory on Health Systems and Policies; 2010.

8. Online published data on chronic diseases prevalence in Italy [Internet]. Italian National Institute of Statistics, ISTAT 2012 [cited 2013 Jun 15]. Available from: http:/dati. istat.it/Index.aspx.

9. Bergh H, Baigi A, Mansson J, Mattsson B, Marklund B. Predictive factors for longterm sick leave and disability pension among frequent and normal attenders in primary health care over 5 years. Public Health. 2007;121(1):25-33, http://dx.doi. org/10.1016/j.puhe.2006.08.018.

10. Hemingway H, Vahtera J, Virtanen M, Pentti J, Kivimaki M. Outcome of stable angina in a working population: The burden of sickness absence. Eur J Cardiovasc Prev Rehabil. 2007;14(3):373-9, http://dx.doi.org/10.1097/01.hjr. 0000230106.01396.a2.

11. Kivimaki M, Leino-Arjas P, Kaila-Kangas L, Virtanen M, Elovainio M, Puttonen S, et al. Increased absence due to sickness among employees with fibromyalgia. Ann Rheum Dis. 2007;66(1):65-9, http://dx.doi.org/10.1136/ $\operatorname{ard} .2006 .053819$.

12. Erickson SR, Kirking DM. A cross-sectional analysis of work-related outcomes in adults with asthma. Ann Allergy Asthma Immunol. 2002;88(3):292-300, http://dx.doi. org/10.1016/S1081-1206(10)62011-X.

13. De Paola M, Scoppa V, Pupo V. Absenteeism in the Italian public sector: The effects of changes in sick leave compensation. Working Paper n. 16. Arcavacata di Rende: Dipartimento di Economia e Statistica, Università della Calabria; 2009 .
14. Italian Ministry of Economy. Survey on working labor force. Roma: Ministero dell'Economia e delle Finanze; 2012.

15. D'Errico A, Costa G. Socio-demographic and work-related risk factors for medium- and long-term sickness absence among Italian workers. Eur J Public Health. 2012;22(5): 683-8, http://dx.doi.org/10.1093/eurpub/ckr140.

16. Del Boca A, Parisi ML. Why does the private sector react like the public to law 133? A microeconometric analysis of sickness absence in Italy. Working Papers n. 1008. Brescia: Brescia University; 2010.

17. Scoppa V. Worker absenteeism and incentives: Evidence from Italy. Manag Decis Econ. 2010;31:503-15, http://dx.doi. org/10.1002/mde.1504.

18. Lundl T, Christensen KB, Vaez M, Labriola M, Josephson M, Villadsen E, et al. Differences in sickness absence in Sweden and Denmark: The cross national HAKNAK study. Eur J Public Health. 2008;19(3):343-9, http://dx.doi. org/10.1093/eurpub/ckn128.

19. Eriksson H, von Celsing AS, Wahlström R, Janson L, Zander V, Wallman T. Sickness absence and self-reported health a population-based study of 43,600 individuals in central Sweden. BMC Public Health. 2008;8:426, http://dx.doi. org/10.1186/1471-2458-8-426.

20. Hansson T, Jensen I. Swedish Council on technology assessment in health care (SBU). Chapter 6. Sickness absence due to back and neck disorders. Scand J Public Health Suppl. 2004;63:109-51, http://dx.doi. org/10.1080/14034950410021862.

21. Coggon D, Ntani G, Vargas-Prada S, Martinez JM, Serra C, Benavides FG, et al. International variation in absence from work attributed to musculoskeletal illness: Findings from the CUPID study. Occup Environ Med. 2013;70(8):575-84, http://dx.doi.org/10.1136/oemed-2012-101316.

22. Kuijer W, Groothoff JW, Brouwer S, Geertzen JH, Dijkstra PU. Prediction of sickness absence in patients with chronic low back pain: A systematic review. J Occup Rehabil. 2006;16(3):439-67, http://dx.doi.org/10.1007/s10926-0069021-8. 
23. Arends I, van der Klink JJ, van Rhenen W, de Boer MR, Bültmann U. Predictors of recurrent sickness absence among workers having returned to work after sickness absence due to common mental disorders. Scand J Work Environ Health. 2014;40(2):195-202, http://dx.doi.org/10.5271/sjweh.3384.

24. Pedersen J, Bjorner JB, Burr H, Christensen KB. Transitions between sickness absence, work, unemployment, and disability in Denmark 2004-2008. Scand J Work Environ Health. 2012;38(6):516-26, http://dx.doi.org/10.5271/sjweh.3293.

25. Ármannsdóttir B, Mårdby AC, Haukenes I, Hensing G. Cumulative incidence of sickness absence and disease burden among the newly sick-listed, a cross-sectional populationbased study. BMC Public Health. 2013;13:329-39, http:// dx.doi.org/10.1186/1471-2458-13-329.

26. Topics on chronic diseases. World Health Organization 2008 [cited 2013 Jun 1]. Available from: http://www.who.int/topics/chronic_diseases/en/.

27. Carneiro IG, Rasmussen CDN, Jørgensen MB, Flyvholm M-A, Olesen K, Madeleine P, et al. The association between health and sickness absence among Danish and non-Western immigrant cleaners in Denmark. Int Arch Occup Environ Health. 2013;86(4):397-405, http://dx.doi. org/10.1007/s00420-012-0773-5.

28. Kronborg CN, Hallas J, Jacobsen IA. Prevalence, awareness, and control of arterial hypertension in Denmark. J Am Soc Hypertens. 2009;3(1):19-24, http://dx.doi.org/10.1016/ j.jash.2008.08.001.

29. Razminia M, Trivedi A, Molnar J, Elbzour M, Guerrero M, Salem Y, et al. Validation of a new formula for mean arterial pressure calculation: The new formula is superior to the standard formula. Catheter Cardiovasc Interv. 2004;63(4): 419-25, http://dx.doi.org/10.1002/ccd.20217.

30. Koenker R. Quantile Regression. New York: Cambridge University Press; 2005, http://dx.doi.org/10.1017/ CBO9780511754098.

31. Soegaard HJ. Undetected common mental disorders in long-term sickness absence. Int J Family Med. 2012;2012: 1-9, http://dx.doi.org/10.1155/2012/474989.
32. Jansson C, Wiberg M, Alexanderson K. Sickness absence due to gastroesophageal reflux diagnoses: A nationwide Swedish population-based study. Scand J Gastroenterol. 2013;48(1): 17-26, http://dx.doi.org/10.3109/00365521.2012.737359.

33. Roskes K, Donders CG, van der Gulden JW. Health-related and work-related aspects associated with sick leave: A comparison of chronically ill and non-chronically ill workers. Int Arch Occup Environ Health. 2005;78(4):270-8, http:// dx.doi.org/10.1007/s00420-004-0596-0.

34. Knudsen AK, Harvey SB, Mykletun A, Øverland S. Common mental disorders and long-term sickness absence in a general working population. The Hordaland Health Study. Acta Psychiatr Scand. 2013;127(4):287-97, http:// dx.doi.org/10.1111/j.1600-0447.2012.01902.x.

35. Overland S, Knapstad M, Wilhelmsen I, Mykletun A, Glozier N. Do gastrointestinal complaints increase the risk for subsequent medically certified long-term sickness absence? The HUSK study. BMC Gastroenterol. 2011;11:88-98, http://dx.doi.org/10.1186/1471-230X-11-88.

36. Stansfeld SA, Fuhrer R, Head J. Impact of common mental disorders on sickness absence in an occupational cohort study. Occup Environ Med. 2011;68(6):408-13, http://dx.doi. org/10.1136/oem.2010.056994.

37. Guh DP, Zhang W, Bansback N, Amarsi Z, Birmingham CL, Anis AH, et al. The incidence of co-morbidities related to obesity and overweight: A systematic review and meta-analysis. BMC Public Health. 2009;9: 88-108, http://dx.doi.org/10.1186/1471-2458-9-88.

38. Maachi M, Piéroni L, Bruckert E, Jardel C, Fellahi S, Hainque B, et al. Systemic low-grade inflammation is related to both circulating and adipose tissue TNFalpha, leptin and IL-6 levels in obese women. Int J Obes Relat Metab Disord. 2004;28(8):993-7, http://dx.doi.org/10.1038/ sj.ijo.0802718.

39. Korpela K, Roos E, Lallukka T, Rahkonen O, Lahelma E, Laaksonen M. Different measures of body weight as predictors of sickness absence. Scand J Public Health. 2013; 41(1):25-31, http://dx.doi.org/10.1177/1403494812468965. 
40. Harvey SB, Glozier N, Carlton O, Mykletun A, Henderson $\mathrm{M}$, Hotopf $\mathrm{M}$, et al. Obesity and sickness absence: results from the CHAP study. Occup Med. 2010;60(5): 362-8, http://dx.doi.org/10.1093/occmed/kqq031.

41. Laaksonen M, Mastekaasa A, Martikainen P, Rahkonen O, Piha K, Lahelma E. Gender differences in sickness absence, the contribution of occupation and workplace. Scand J Work Environ Health. 2010;36(5):394-403, http://dx.doi. org/10.5271/sjweh.2909.

42. Bekker MH, Rutte CG, van Rijswijk K. Sickness absence: A gender-focused review. Psychol Health Med. 2009;14(4): 405-18, http://dx.doi.org/10.1080/13548500903012830.

43. Duijts SF, Kant I, Swaen GM, van den Brandt PA, Zeegers MP. A meta-analysis of observational studies identifies predictors of sickness absence. J Clin Epidemiol. 2007;60(11):1105-15, http://dx.doi.org/10.1016/j.jclinepi. 2007.04.008.

44. Lerner DJ, Amick BC 3rd, Malspeis S, Rogers WH. A national survey of health-related work limita- tions among employed persons in the United States. Disabil Rehabil. 2000;22(5):225-32, http://dx.doi. org/10.1080/096382800296791.

45. Munir F, Yarker J, Haslam C, Long H, Leka S, Griffiths A, et al. Work factors related to psychological and health-related distress among employees with chronic illnesses. J Occup Rehabil. 2007;17(2):259-77, http://dx.doi.org/10.1007/ s10926-007-9074-3.

46. Westhoff G, Dörner T, Zink A. Fatigue and depression predict physician visits and work disability in women with primary Sjögren's syndrome: Results from a cohort study. Rheumatology (Oxford). 2012;51(2):262-9, http://dx.doi. org/10.1093/rheumatology/ker208.

47. Ferrie JE, Kivimäki M, Westerlund H, Head J, Melchior M, Singh-Manoux A, et al. Differences in the association between sickness absence and long-term sub-optimal health by occupational position: A 14-year follow-up in the GAZEL cohort. Occup Environ Med. 2011;68(10):729-33, http://dx.doi.org/10.1136/oem.2010.060210.

This work is available in Open Access model and licensed under a Creative Commons Attribution-NonCommercial 3.0 Poland License - http://creativecommons.org/ licenses/by-nc/3.0/pl/deed.en. 